\title{
Osthole inhibits proliferation of human breast cancer cells by inducing cell cycle arrest and apoptosis
}

\author{
Lintao Wang ${ }^{1}$, Yanyan Peng ${ }^{2}$, Kaikai Shi ${ }^{2}$, Haixiao $\mathrm{Wang}^{3}$, Jianlei Lu², Yanli $\mathrm{Li}^{1}$, Changyan Ma, \\ ${ }^{1}$ Department of Biochemistry and Molecular Biology, Nanjing Medical University, Nanjing, Jiangsu 210029, China; \\ ${ }^{2}$ Department of Developmental Genetics, Nanjing Medical University, Nanjing, Jiangsu 210029, China; \\ ${ }^{3}$ Department of General Surgery, Huaian No. 1 People's Hospital Affiliated to Nanjing Medical University, Huaian, \\ Jiangsu 223300, China.
}

\begin{abstract}
Recent studies have revealed that osthole, an active constituent isolated from the fruit of Cnidium monnieri $(L$. $)$ Cusson, a traditional Chinese medicine, possesses anticancer activity. However, its effect on breast cancer cells so far has not been elucidated clearly. In the present study, we evaluated the effects of osthole on the proliferation, cell cycle and apoptosis of human breast cancer cells MDA-MB 435. We demonstrated that osthole is effective in inhibiting the proliferation of MDA-MB 435 cells, The mitochondrion-mediated apoptotic pathway was involved in apoptosis induced by osthole, as indicated by activation of caspase- 9 and caspase-3 followed by PARP degradation. The mechanism underlying its effect on the induction of Gl phase arrest was due to the up-regulation of p53 and p21 and down-regulation of Cdk2 and cyclin D1 expression. Were observed taken together, these findings suggest that the anticancer efficacy of osthole is mediated via induction of cell cycle arrest and apoptosis in human breast cancer cells and osthole may be a potential chemotherapeutic agent against human breast cancer.
\end{abstract}

Keywords: osthole, breast cancer, proliferation, cell cycle, apoptosis

\section{Introduction}

Breast cancer is an important public health problem worldwide and continues to rank as one of the top causes of death in women ${ }^{[1]}$. Despite diagnostic and therapeutic advances the long-term prognosis of breast cancer remains poor. Recently, more attention has been paid to the natural products in the treatment of breast cancer because they are associated with low toxicity. For example, genistein, isoliquiritigenin and resveratrol have been reported to be potentially excellent candidates for use as chemopreventive agents

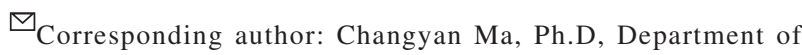
Developmental Genetics, Nanjing Medical University, 140 Hanzhong Road, Nanjing, Jiangsu 210029, China. Tel: +86-25-86862137, E-mail: cyma@njmu.edu.cn.
}

against estrogen receptor (ER) positive breast cancer $^{[2-4]}$. However, ER-negative breast cancers are also more aggressive and have poorer clinical outcomes than ER-positive cancers ${ }^{[5]}$. Therefore, identifying novel drugs for the treatment of ER negative breast cancer is urgently required.

Osthole (7-methoxy-8-isopentenoxycoumarin) is a natural coumarin and bioactive compound isolated from the fruit of Cnidium monnieri (L.) Cusson. It has been reported that osthole possesses vasorelaxant ${ }^{[6]}$, anti-osteoporotic ${ }^{[7]}$ and anti-inflammatory effects ${ }^{[8,9]}$.

Received 16 October 2012, Revised 20 November 2012, Accepted 04 December 2012, Epub 20 December 2012

The authors reported no conflicts of interest. 
Recently, osthole has received more attention for its anti-tumor activity ${ }^{[10-13]}$. However, the effects of osthole on breast cancer cells and the underlying mechanisms are poorly understood.

In the present study, we examined the effects of osthole on the proliferation, cell cycle and apoptosis of MDA-MB 435 cells, which are ER-negative and highly metastatic human breast cancer cells.

\section{Materials and methods}

\section{Reagents}

Osthole was obtained from Jiangsu Institute for Food and Drug Control (Nanjing, Jiangsu, China). 3-(4,5-Dimethyl-2-thiazolyl)-2,5-diphenyltetrazolium bromide (MTT) was purchased from SigmaAldrich (St. Louis, MO, USA). Antibodies for p53 and p21, cyclin D1, Cdk2, Bax, Bcl-2, pro-caspase-9 and pro-caspase-3 were from Bioworld Technology (West Palm Beach, USA). Antibody for PARP was from Cell Signaling Technology (Beverly, MA, USA). Anti- $\beta$-actin antibody and anti-mouse and anti-rabbit antibodies conjugated to horseradish peroxidase were from Santa Cruz Biotechnology (Santa Cruz, CA, USA).

\section{Cell culture}

MDA-MB 435 cells were cultured in Dulbecco's modified eagle medium (DMEM) supplemented with $10 \%$ fetal bovine serum (FBS), $100 \mathrm{U} / \mathrm{mL}$ of penicillin and $100 \mu \mathrm{g} / \mathrm{mL}$ of streptomycin. Cultured cells were incubated at $37^{\circ} \mathrm{C}$ in a humid chamber at $5 \% \mathrm{CO}_{2}$.

\section{MTT assay}

MDA-MB 435 cells at the logarithmic growth phase were collected and seeded in 96-well tissue culture plates $\left(8 \times 10^{3}\right.$ cells/well) and allowed to adhere overnight. After the cells were treated with osthole $(0,20$, $40,60,80$ or $100 \mathrm{~mol} / \mathrm{L}$ ) for 24,36 or 48 hours, $20 \mu \mathrm{L}$ of MTT $(5 \mathrm{mg} / \mathrm{mL})$ was added into each well and the cells were incubated at $37^{\circ} \mathrm{C}$ for 4 hour. followed by $150 \mu \mathrm{L}$ of dimethyl sulfoxide (DMSO) and incubated for 1 hour at $37^{\circ} \mathrm{C}$. The absorbance at $570 \mathrm{~nm}$ was measured using a Synergy HT plate reader (Bio-Tek Instruments, Winooski, VT, USA).

\section{Flow cytometry}

After treatment with osthole, MDA-MB 435 cells were resuspended in $70 \%$ cold ethanol and incubated on ice for at least 1 hour. Cells were resuspended in FACS buffer $(0.5 \mathrm{mg} / \mathrm{mL}$ RNase A, $0.38 \mathrm{mmol} / \mathrm{L} \mathrm{so-}$ dium citrate and $0.15 \mathrm{mg} / \mathrm{mL}$ propidium iodide) and incubated for 30 minutes at $37^{\circ} \mathrm{C}$ in the dark. Cell cycle profile was analyzed with a FACScan flow cytometer (Becton Dickinson, San Jose, CA).

To estimate the number of apoptotic cells, MDA-MB 435 cells treated with osthole were harvested and centrifuged at $1000 \mathrm{rpm}$ for 10 minutes, and washed with PBS. Then the cells were fluorescently labeled with 20 $\mu \mathrm{L}$ of $1 \times$ binding buffer $(10 \mathrm{mmol} / \mathrm{L}$ Hepes $/ \mathrm{NaOH}, 140$ $\mathrm{mmol} / \mathrm{L} \mathrm{NaCl}, 2.5 \mathrm{mmol} / \mathrm{L} \mathrm{CaCl} 2, \mathrm{pH} 7.4), 5 \mu \mathrm{L}$ of annexin V-FITC and $5 \mu \mathrm{L}$ of PI. After incubation at room temperature for 15 minutes in dark, the cells were analyzed immediately by FACScan flow cytometer.

\section{Western blotting assays}

MDA-MB 435 cells were treated with osthole $(0$, 25,50 or $100 \mu \mathrm{mol} / \mathrm{L}$ ) for 36 hours. Cells were washed with PBS and lysed with RIPA buffer $(50 \mathrm{mmol} / \mathrm{L}$ Tris, $\mathrm{pH} 7.4,0.5 \%$ NP-40 and $0.01 \%$ SDS)) plus protease inhibitors (Roche). Total protein $(30 \mu \mathrm{g})$ was boiled for 5 minutes in $1 \times$ loading buffer, chilled on ice and then separated on $10 \%$ sodium dodecyl sulfate-polyacrylamide gels and electrobloted onto polyvinylidene fluoride membranes (Millipore, USA). Non-specific protein interactions were blocked by incubation with $5 \%$ nonfat milk in TBST buffer $(50 \mathrm{mmol} / \mathrm{LTris}-\mathrm{HCl}$, $150 \mathrm{mmol} / \mathrm{L} \mathrm{NaCl}, 0.05 \%$ Tween $20, \mathrm{pH}$ 7.6) at $4{ }^{\circ} \mathrm{C}$ for 1 hour. The membranes were incubated overnight with the primary antibodies in the blocking buffer at $4{ }^{\circ} \mathrm{C}$. Unbound antibody was removed by washes in TBST buffer for three times (10 minutes/time). Membranes were then incubated with horseradish peroxideconjugated secondary antibody for 1 hour at room temperature followed by washes with TBST buffer for three times (10 minutes/time). The blots were developed with ECL reagent (Applygen).

\section{Statistical analysis}

All of the experiments were independently repeated at least three times. Comparisons between control and treatment groups were analyzed by one-way ANOVA and Tukey's post-hoc test or Student's $t$ test. A probability value of $P<0.05$ was considered statistically significant.

\section{Results}

\section{Osthole inhibited the proliferation of MDA- MB 435 cells}

To determine whether osthole has proliferation inhibitory effects on breast cancer cells, MDA-MB 435 cells were treated with different concentrations of osthole $(0,20,40,60,80$ and $100 \mu \mathrm{mol} / \mathrm{L})$ for 24 , 36 and 48 hours, respectively. Cellular proliferation was evaluated by MTT assay. As shown in Fig.1, the 


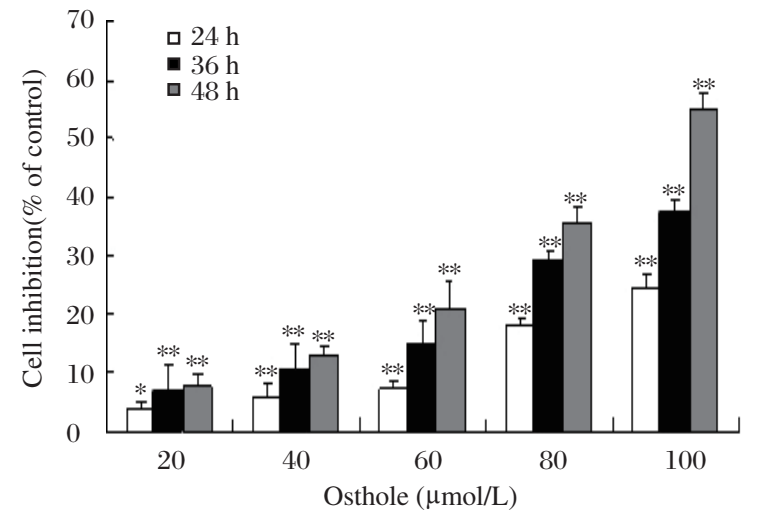

Fig 1. Effects of osthole on the proliferation of MDAMB 435 cells. $P<0.05,{ }^{* *} P<0.01$ vs. control $(0 \mu \mathrm{mol} / \mathrm{L}$ osthole)

proliferation of MDA-MB 435 cells was inhibited by osthole in a dose- and time-dependent manner. When MDA-MB 435 cells were treated with osthole $(0,20,40,60,80$ and $100 \mu \mathrm{mol} / \mathrm{L})$ for 48 hours, the growth inhibitory rate was $(7.8 \pm 2.2) \%,(13.0 \pm 1.2) \%$, $(21.0 \pm 4.5) \%$, $(35.6 \pm 2.5) \%$ and $(54.8 \pm 2.8) \%$, respectively. When the cells were treated with 100 $\mu \mathrm{mol} / \mathrm{L}$ of osthole for 24,36 and 48 hours, the growth inhibitory rate was $(24.6 \pm 1.9) \%, 37.2 \pm 2.4) \%$ and $(54.8 \pm 1.2) \%$, respectively.

\section{Osthole induced G1/S arrest of MDA-MB 435 cells}

To elucidate whether the proliferation inhibitory effect of osthole was due to cell cycle arrest, MDAMB 435 cells were treated with osthole $(0,25,50$ and $100 \mu \mathrm{mol} / \mathrm{L}$ ) for 36 hours and stained with propidium iodide for flow cytometry analysis. As shown in Fig. 2and Table 1, the Gl phase cell population of osthole-treated cells increased significantly in a dosedependent manner. Treatment with $100 \mu \mathrm{mol} / \mathrm{L}$ of osthole led to Gl phase accumulation by $72.8 \%$, which

A

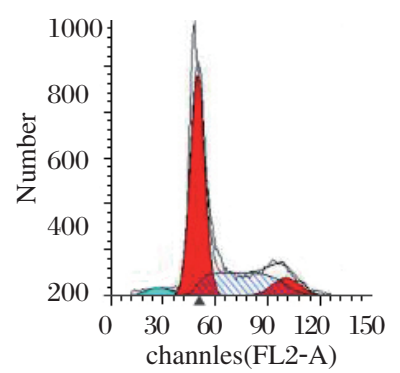

B

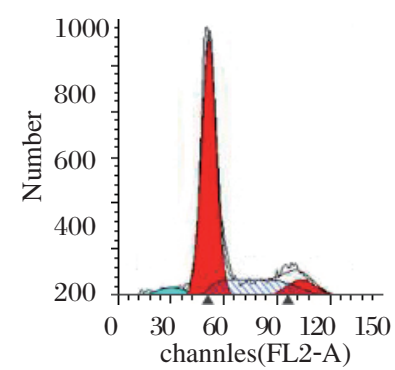

was accompanied by a corresponding reduction in the percentages of cells in S phase (Fig. 2 and Table 1). Moreover, $100 \mu \mathrm{mol} / \mathrm{L}$ osthole significantly increased the sub-G1, suggesting that inducing apoptosis may be also population involved in osthole mediated inhibition of the proliferation of MDA-MB 435 cells.

\section{Osthole induced apoptosis of MDA-MB 435 cells}

To determine whether cells treated with osthole underwent apoptosis in addition to cell cycle arrest, MDA-MB 435 cells were treated with osthole and stained with annexin $\mathrm{V}$ and propidium iodide for flow cytometry analysis. As shown in Fig. 3, the number of apoptotic cells was increased compared with control. When MDA-MB 435 cells were treated with $100 \mu \mathrm{M}$ of osthole for 36 hours, the proportion of the apoptotic cells was over three times higher than the control.

\section{Effects of osthole on cell cycle control proteins} and apoptosis-associated proteins

As shown in Fig. 4, the expression of p53 and p21 were obviously increased, and the expression of Cdk2 and cyclin Dl were significantly decreased after osthole treatment. To explore the mechanism by which osthole induced apoptosis, we analyzed the levels of pro-caspase-3 and PARP by Western blotting analysis. As shown in Fig. 5, pro-caspase-3 in MDA-MB 435 cells was reduced in a dose-dependent manner after treatment with osthole. In addition, full-length PARP was decreased progressively, Caspase-9 is an important intracellular amplifier of caspase signaling downstream of mitochondria. To further define whether osthole induces apoptosis via the intrinsic pathway, the level of pro-caspase-9 was examined. As shown in Fig. 5, the level of pro-caspase-9 in MDA-MB 435 cells was reduced in a dose-dependent manner after treat-

$\mathrm{C}$

D
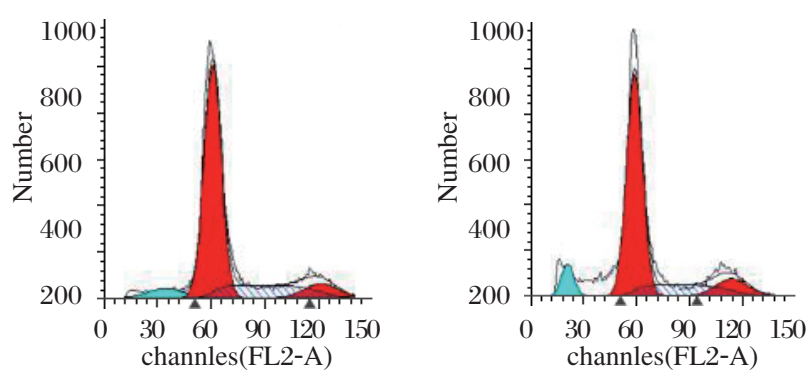

Fig 2. Effects of osthole on the cell cycle distribution of MDA-MB 435 cells. MDA-MB 435 cells were treated with osthole for 36 hours. Cells were harvested and prepared for the cell cycle detection using flow cytometer as described in the Materials and Methods. Images are shown for one of three separate experiments. A: Control group. B: osthole $25 \mu \mathrm{mol} / \mathrm{L}$. C: osthole $50 \mu \mathrm{mol} / \mathrm{L}$. D: osthole $100 \mu \mathrm{mol} / \mathrm{L}$. 
Table 1 Cell cycle distribution ( $\%$ ) of MDA-MB 435 cells after osthole treatment.

\begin{tabular}{lcccc}
\hline & Control & $25(\mu \mathrm{mol} / \mathrm{L})$ & $50(\mu \mathrm{mol} / \mathrm{L})$ & $100(\mu \mathrm{mol} / \mathrm{L})$ \\
\hline G1 & $59.63 \pm 0.22$ & $67.95 \pm 1.13$ & $71.94 \pm 0.29$ & $72.81 \pm 0.78$ \\
S & $30.13 \pm 0.075$ & $22.44 \pm 0.49$ & $18.85 \pm 0.395$ & $17.14 \pm 0.44$ \\
G2/M & $10.25 \pm 0.295$ & $9.62 \pm 0.63$ & $9.22 \pm 0.1$ & $10.06 \pm 1.22$ \\
\hline
\end{tabular}

ment with osthole.

\section{Osthole upregulated Bax and downregulated}

\section{Bcl-2 expression}

The mitochondrial intrinsic pathway of apoptosis is regulated by the balance between the pro- and anti apoptotic Bcl-2 family of proteins ${ }^{[14-16]}$. We performed immunoblot analysis to determine whether the apoptosis induced by osthole was associated with changes of antiapoptotic (Bcl-2) and proapoptotic (Bax) proteins. As shown in Fig. 6, the expression of Bax was increased and the expression of Bcl-2 was decreased following osthole treatment. These results suggest

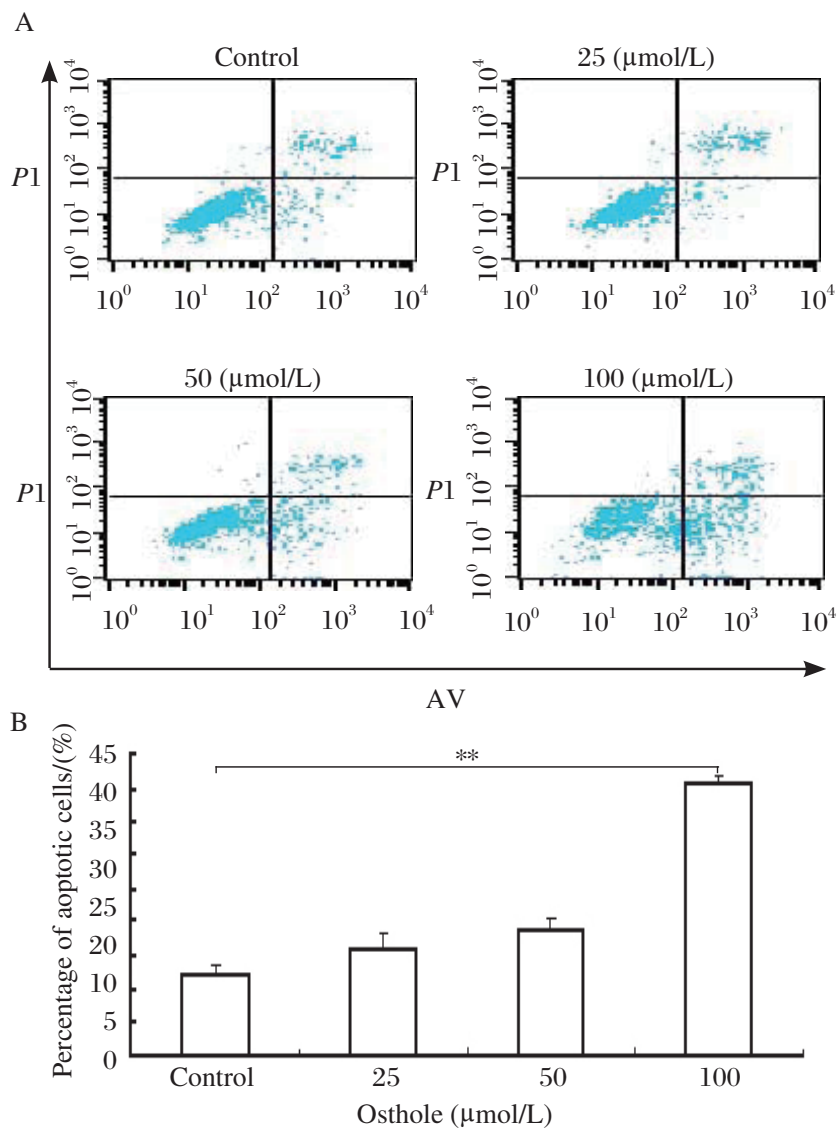

Fig 3. Effects of osthole on the apoptosis of MDAMB 435 cells. MDA-MB 435 cells were treated with osthole $(0,25,50$ and $100 \mu \mathrm{mol} / \mathrm{L})$ for 36 hours. Cells were harvested and analyzed with annexin $\mathrm{V}$ and propidium iodide using flow cytometer as described in the Methods. A: Representative histograms of three separate experiments. B: Results of three separate experiments are shown. Values are expressed as mean \pm SD. ${ }^{* *} P<0.01$. that osthole induces apoptosis by suppression of antiapoptotic protein expression and promotion of proapoptotic protein expression.

\section{Discussion}

Natural products have always been important resources either as therapeutic agents or as lead compounds for the production of pharmaceutical compounds ${ }^{[17]}$. Because of its significant and diverse pharmacological activities, including anticancer, antisteoporotic, and antiproliferative, osthole has recently been considered as a very promising natural lead compound for new drug discovery. The anticancer effect of osthole has been reported in a few studies ${ }^{[18-22]}$. It is reported recently that osthole is able to inhibit the migration and invasion of breast cancer cells ${ }^{[20]}$. In the present study, we demonstrated that the possible roles of osthole on MDA-MB 435 cells, an estrogen receptor negative and highly metastatic human breast cancer cell line, were 1) to inhibit the proliferation of cells in a dose- and time-dependent manner, 2) to arrest the cell cycle at G1 phase via the up-regulation of p53 and p21 as well as down-regulation of cyclin D1 and Cdk2, and 3 ) to induce apoptosis via activation of caspase-9 and caspase-3 followed by cleavage of PARP.

In the proliferation assay, we clearly demonstrated that osthole inhibited the proliferation of MDA-MB 435 cells in a dose- and time- dependent manner (Fig. 2). The inhibition rate was $54.8 \%$ when the cells were treated with $100 \mu \mathrm{mol} / \mathrm{L}$ of osthole for 48 hours. These results indicate that osthole may have significant anti-cancer effect on human breast cancer cells. To characterize the underlying mechanisms by which osthole inhibits the proliferation of MDA-MB 435 cells, we tested whether osthole had the capacity to block cell cycle progression by flow cytometric analysis. The results showed that upon treatment with $100 \mu \mathrm{M}$ of osthole for 36 hours, the proportion of cells in Gl phase increased to $72.8 \%$, being remarkablely higher than that of the control. Therefore, Gl phase arrest may be one of the causes which lead to the inhibition of MDA-MB 435 cell proliferation by osthole. Our results of flow cytometry analyses also showed that osthole markedly induce apoptosis of MDA-MB 435 cells, suggesting that inducing apoptosis may also contribute to the antiproliferative function of osthole against breast cancer cells. 

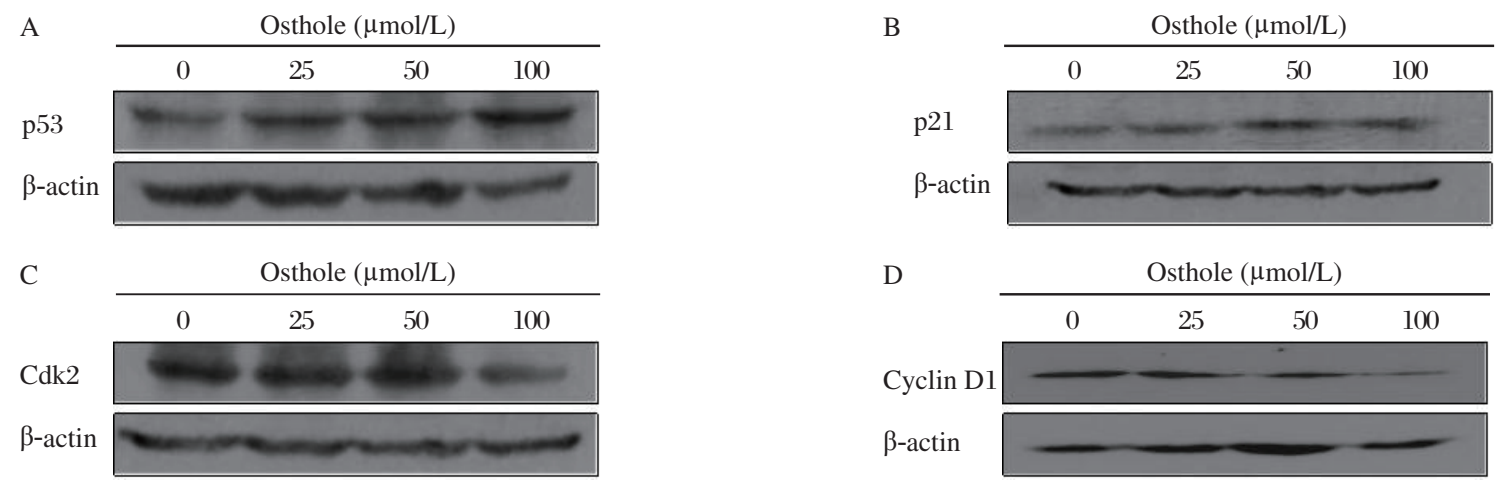

Fig 4. Effects of osthole on the expression of p53 and p21 as well as Cdk2 and cyclin D1. MDA-MB 435 cells were treated with osthole $(0,25,50$ and $100 \mu \mathrm{mol} / \mathrm{L})$ for 36 hours. Cell lysates were immunoblotted with anti-p53 (A) anti-p21 (B) antiCdk2 (C) and anti-cyclin D1 (D) antibodies, respectively. $\beta$-actin served as loading control.

Cell cycle control is a highly regulated process that involves a complex cascade of events. Modulation of the expression and function of the cell cycle regulatory proteins including Cdks and cyclins provides an important mechanism for the inhibition of growth $^{[18-20]}$. To understand the mechanism by which osthole inducing G1 phase arrest, Cdk2 and cyclin D1 which are key mediators involved in controlling Gl phase progression and G1/S phase transition. The results showed that treatment with osthole led to down-regulation of Cdk2 and cyclin Dl. In addition to the binding of cyclins, Cdk activity is modulated by positive and negative interfering factors. Among these factors, p21 is one of the most interesting inhibitors, since it has multiple binding capacities not only for $\mathrm{CDK}^{[21,22]}$ but also for cyclins ${ }^{[23]}$. our results showed that p21 was up-regulated after MDA-MB 435 cells were treated with osthole. The p53, as a tumor suppressor protein, governs the long-term cellular response to genotoxic stress by inducing a p21-dependent cell cycle arrest or apopto$\operatorname{sis}^{[24,25]}$. Furthermore, we examined the expression of p53 and found that p53 was up-regulated after osthole treatment. These data suggest that Gl phase arrest induced by osthole was associated with the up-regulation of $\mathrm{p} 53, \mathrm{p} 21$ and down-regulation of $\mathrm{Cdk} 2$ and cyclin D1. However, it was reported that osthole inhibited the growth of human lung cancer A549 cells by inducing
$\mathrm{G} 2 / \mathrm{M}$ arrest ${ }^{[13]}$, indicating that the mechanism by which osthole induces cell cycle arrest may be cell type-dependent.

Apoptosis plays important roles in the development, homeostasis of cell populations and pathogenesis of diseases $^{[26]}$. It is mediated either through death receptors (extrinsic pathway) or through the mitochondrial pathway (intrinsic pathway) ${ }^{[27-29]}$. Both extrinsic pathway and intrinsic pathway involve the activation of members of the caspase family of cysteine proteases in a hierarchical cascade, with caspases functioning as triggers and executioners of the apoptotic process. Activation of caspase-9 is involved in the intrinsic pathway, whereas activation of caspase-8 is involved in the extrinsic pathway. Caspase-3 is a major executioner protease, responsible for initiating the apoptotic program and it may be activated either by caspase- 8 or by caspase $-9^{[30,31]}$. Cleavage of PARP, which is a wellknown substrate for caspase-3 in the apoptotic events, facilitates cellular disassembly and serves as a marker of cells undergoing apoptosis ${ }^{[14]}$. Activation of caspase-9 and caspase-3 is usually regarded as a hallmark of mitochondrial cell death ${ }^{[32]}$. To explore the possible mechanisms of osthole induced apoptosis, we examined the levels of pro-caspase-9, pro-caspase-3 and PARP by Western blotting. The results showed that treatment with osthole decreased pro-caspase-9, pro-
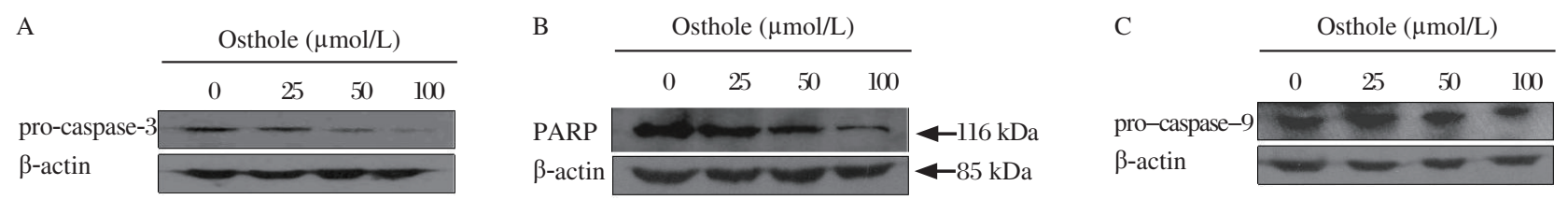

Fig 5. Effects of osthole on the levels of pro-caspase-3, PARP and pro-caspase-9. MDA-MB 435 cells were treated with osthole $(0,25,50$ and $100 \mu \mathrm{mol} / \mathrm{L})$ for 36 hours. Cell lysates were immunoblotted with anti-pro-caspase-3 (A) anti-PARP (B) and anti-pro-caspase-9 (C) antibodies, respectively. $\beta$-actin served as loading control. 
A

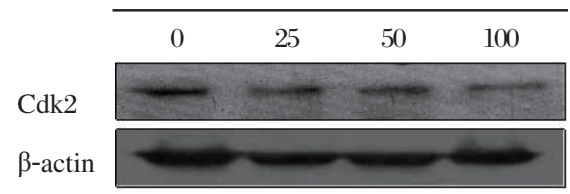

B $\quad$ Osthole $(\mu \mathrm{mol} / \mathrm{L})$

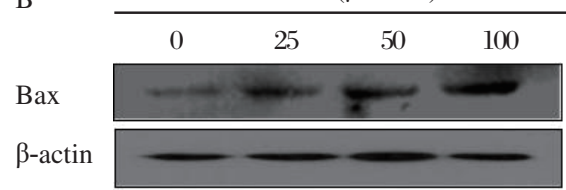

Fig 6. Effects of osthole on the levels of Bcl-2 (A) and Bax (B). MDA-MB 435 cells were treated with osthole ( 0 , 25,50 and $100 \mu \mathrm{mol} / \mathrm{L}$ ) for 36 hours. Cell lysates were immunoblotted with anti-Bcl-2 and anti-Bax antibodies, respectively. $\beta$-actin served as loading control.

caspase- 3 and caused specific cleavage of the caspase- 3 substrate PARP, indicating that the mitochondrial signaling pathway may be involved in osthole induced apoptosis. Our results of Bcl-2/Bax examination are also consistent with the data that osthole induces apoptosis by down-regulating the expressions of $\mathrm{Bcl}-2$ and up-regulating the expressions of Bax in human lung cancer A549 cells ${ }^{[13]}$.

In summary, our study demonstrated that osthole is effective in inhibiting cell proliferation, and inducing Gl phase arrest and apoptosis in breast cancer cells MDA-MB 435. Gl phase arrest induced by osthole was associated with the up-regulation of p53, p21 and down-regulation of Cdk2, and cyclin D1. Treatment with osthole led to the activation of caspase 9 and caspase 3 followed by PARP degradation, suggesting that the mitochondrion-mediated apoptotic pathway may be involved in the mechanism of apoptosis induced by osthole. Taken together, these results suggest that osthole may be a potential candidate as chemotherapeutic agent against human breast cancer.

\section{Acknowledgement}

This work was supported by grant from the Natural Science Foundation of Jiangsu Province (No. BK2011140).

\section{References}

[1] Falandry C, Canney PA, Freyer G, et al. Role of combination therapy with aromatase and cyclooxygenase-2 inhibitors in patients with metastatic breast cancer. Ann Oncol 2009;20(4):615-620.

[2] Barnes S. Effect of genistein on in vitro and in vivo model of cancer. J nutr 1995; 125(3 Suppl):777s-783s.
[3] Ye L, Gho WM, Chan FL, et al. Dietary administration of the licorice flavonoid isoliquiritigenin deters the growth of MCF- 7 cells overespressing aromatase. Int J can 2009;124(5):1028-1036.

[4] Wang Y, Lee KW, Chan FL, et al. The red wine polyphenol reseveratrol displays bilevel inhibition on aromatase in breast cancer cells. Toxicol Sci 2006;92(1): 71-77.

[5] Seo HS, Ju JH, Jang K, et al. Induction of apoptotic cell death by phytoestrogens by up-regulating the levels of phospho-p53 and p21 in normal and malignant estrogen receptor $\alpha$-negative breast cells. Nutr Res 2011;31(2):139146.

[6] Ko FN, Wu TS, Liou MJ, et al. Vasorelaxation of rat thoracic aorta caused by osthole isolated from Angelica pubescens. Eur J Pharmacol 1992; 219(1): 29-34.

[7] Zhang Q, Qin L, He W, et al. Coumarins from Cnidium monnieri and their antiosteoporotic activity. Planta Med 2007;73(1):13-19.

[8] Zimecki M, Artym J, Cisowski W, et al. Immunomodulatory and anti-inflammatory activity of selected osthole derivatives. Z Naturforsch C 2009; 64(5-6):361-368.

[9] Okamoto T, Yoshida S, Kobayashi T,et al. Inhibition of concanavalin A-induced mice hepatitis by coumarin derivatives. Jpn J Pharmacol 2001;85(1):95-97.

[10] Okamoto T, Kobayashi T, Yoshida S. Chemical aspects of coumarin compounds for the prevention of hepatocellular carcinomas. Curr Med Chem Anticancer Agents 2005;5(1):47-51.

[11] Chou SY, Hsu CS, Wang KT, et al. Antitumor effects of Osthol from Cnidium monnieri: an in vitro and in vivo study. Phytother Res 2007;21(3):226-230.

[12] Lin VC, Chou CH, Lin YC, et al. Osthole suppresses fatty acid synthase expression in HER2-overexpressing breast cancer cells through modulating Akt/mTOR pathway. J Agric Food Chem 2010;58(8):4786-4793.

[13] Xu X, Zhang Y, Qu D, et al. Osthole induces G2/M arrest and apoptosis in lung cancer A549 cells by modulating PI3K/Akt pathway. J Exp Clin Cancer Res 2011; 30: 3340.

[14] Oliver FJ, de la Rubia G, Rolli V, et al. Importance of poly(ADP-ribose) polymerase and its cleavage in apoptosis. Lesson from an uncleavable mutant. J Biol Chem 1998; 273(50): 33533-33539.

[15] Wang X. The expanding role of mitochondria in apoptosis. Genes Dev 2001; 15(22): 2922-2933.

[16] Cory S, Adams JM. The Bcl2 family: regulators of the cellular life-or-death switch. Nat Rev Cancer 2002;2(9):647-656.

[17] You L, Feng S, An R, et al. Osthole: a promising lead compound for drug discovery from a traditional Chinese medicine (TCM). Nat Prod Commun 2009; 4(2):297-302.

[18] Sherr CJ. Cancer cell cycles. Science 1996;274(5293):16721677.

[19] Sherr CJ, Roberts JM. CDK inhibitors: positive and negative regulators of G1-phase progression. Genes Dev 1999;13(12):1501-1512.

[20] Sherr CJ. The Pezcoller lecture: Cancer cell cycles revis- 
ited. Cancer Res 2000; 60(14):3689-3695.

[21] Harper JW, Adami GR, Wei N, et al. The p21 Cdkinteracting protein $\mathrm{Cipl}$ is a potent inhibitor of G1 cyclindependent kinases. Cell 1993;75(4):805-816.

[22] Xiong Y, Hannon GJ, Zhang H, et al. p21 is a universal inhibitor of cyclin kinases. Nature 1993;366(6456):701-704.

[23] Fotedar R, Fitzgerald P, Rouselle T,et al. p21 contains independent binding sites for cyclin and cdk2: both sites are required to inhibit cdk2 kinase activity. Oncogene 1996;12(10):2155-2164.

[24] Levine AJ, Oren M. The first 30 years of p53: growing ever more complex. Nat Rev Cancer 2009;9(10):749-758.

[25] el-Deiry WS. p21/p53, cellular growth control and genomic integrity. Curr Top Microbiol Immunol 1998; 227: 121-137.

[26] Hofman P, Auberger P. Roles and mechanisms of apop- tosis in infectious diseases. Ann Pathol 2000;20(4):313322.

[27] Danial NN, Korsmeyer SJ. Cell death: critical control points. Cell 2004;116(2):205-219.

[28] Green DR, Kroemer G. The pathophysiology of mitochondrial cell death. Science 2004;305(5684):626-629.

[29] Jin Z, El-Deiry WS. Overview of cell death signaling pathways. Cancer Biol Ther 2005;4(2):139-163.

[30] Shiozaki EN, Shi Y. Caspases, IAPs and Smac/DIABLO: mechanisms from structural biology. Trends Biochem Sci 2004;29(9):486-494.

[31] Shi Y. Caspase activation: revisiting the induced proximity model. Cell 2004; 117(7):855-858.

[32] Joza N, Susin SA, Daugas E, et al. Essential role of the mitochondrial apoptosis-inducing factor in programmed cell death. Nature 2001; 410(6828): 549-554.

\section{CLINICAL TRIAL REGISTRATION}

The Journal requires investigators to register their clinical trials in a public trials registry for publication of reports of clinical trials in the Journal. Information on requirements and acceptable registries is available at www.icmje.org/faq_clinical.html. 